Canadian

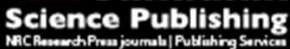

Applied Physiology, Nutrition, and Metabolism Physiologie appliquée, nutrition et métabolisme

\title{
THE EFFECT OF MODERATE CONSUMPTION OF NON- NUTRITIVE SWEETENERS ON GLUCOSE TOLERANCE AND BODY COMPOSITION IN RATS
}

\begin{tabular}{|r|l|}
\hline Journal: & Applied Physiology, Nutrition, and Metabolism \\
\hline Manuscript ID & apnm-2017-0120.R2 \\
\hline Manuscript Type: & Brief communication \\
\hline Date Submitted by the Author: & 24-Jun-2017 \\
\hline Complete List of Authors: & $\begin{array}{l}\text { Tovar, Ashley; University of California Davis, Nutritional Biology; University } \\
\text { of Nevada Las Vegas, } \\
\text { Navalta, James; University of Las Vegas- Nevada, Kinesiology and Nutrition } \\
\text { Science } \\
\text { Kruskall, Laura; University of Las Vegas } \\
\text { Young, John; UNLV, Department of Kinesiology \& Nutrition Sciences; }\end{array}$ \\
\hline $\begin{array}{r}\text { Is the invited manuscript for } \\
\text { consideration in a Special } \\
\text { Issue? : }\end{array}$ & $\begin{array}{l}\text { body composition < body composition, carbohydrate metabolism < } \\
\text { metabolism, dietary intake < energy regulation }\end{array}$ \\
\hline Keyword & \\
\hline \multicolumn{2}{|c}{} \\
\hline
\end{tabular}


THE EFFECT OF MODERATE CONSUMPTION OF NON-NUTRITIVE SWEETENERS ON GLUCOSE TOLERANCE AND BODY COMPOSITION IN RATS

Ashley P. Tovar, James W. Navalta, Laura J. Kruskall, and John C. Young

Department of Kinesiology and Nutrition Sciences

University of Nevada, Las Vegas

4505 S. Maryland Parkway, Las Vegas, NV 89154-3034

Ashley Tovar; aptovar@ucdavis.edu

James Navalta; james.navalta@unlv.edu

Laura Kruskall; laura.kruskall@unlv.edu

Corresponding Author: John C. Young

Department of Kinesiology and Nutrition Sciences

University of Nevada, Las Vegas

4505 S. Maryland Parkway, Las Vegas, NV 89154-3034

Phone: 702-895-4626

Fax: 702-895-1500

John.young@unlv.edu 


\section{Abstract}

Glucose tolerance and body composition were determined in male rats given non-nutritive sweeteners (NNS) (aspartame or sucralose) in drinking water. AUC for glucose and insulin with NNS did not differ from control. NNS treatment had no effect on weight gain or percent body fat. Epididymal fat pad mass was higher with aspartame and the ratio of trunk to total fat was less with sucralose versus control, suggesting that NNS consumption altered body fat distribution.

Key words; Body Composition, Dietary Intake, Carbohydrate Metabolism 
Introduction

Non-nutritive sweeteners (NNS) have been introduced as replacements for sugar sweetening in beverages, reducing energy intake while maintaining sweetness. However, the consequences of this intervention on metabolic function are unclear. Although presumed to be metabolically inert, NNS consumption has been associated with weight gain and altered glucose tolerance in some human and animal studies (Fowler 2016), suggesting that NNS may, in fact, have metabolic effects, including an altered ability to compensate for calories expected by the sweet taste. Aspartame, a methyl ester of aspartic acid and phenylalanine, and sucralose, a chlorinated derivative of sucrose, are widely used sweeteners in beverages and foods; their use has been linked to obesity, metabolic syndrome, and diabetes (Fowler 2016). The purpose of this study was to examine the effects of low-dose aspartame or sucralose treatment on weight gain, body composition, and glucose tolerance in rats where NNS delivery method and diet are consistent.

\section{$\underline{\text { Methods }}$}

Male Sprague-Dawley rats ( $n=30$ ) (Taconic Biosciences, Rensselaer, N.Y., U.S.A.) were housed in pairs in the Laboratory Animal Care Facility on a $12 \mathrm{~h}$ light/dark cycle with ad libitum access to standard rat chow (PicoLab Rodent Diet 20; Lab Diet, St Louis, MO) and water. Animals were randomly assigned to one of three groups, aspartame $(n=10)$, sucralose $(n=10)$, or control $(n=10)$. Commercially available aspartame (Merisant, Chicago, IL) and sucralose (Heartland Food Products Group, Carmel, IN) were administered in drinking water. NNS doses were based on the average daily water intake of rats, 80-110 $\mathrm{ml} / \mathrm{kg} /$ day (Baker et al. 2006), and NNS groups mean body weight. Doses for aspartame ranged from 6-8 $\mathrm{mg} / \mathrm{kg} /$ day in wk 1 to $15-21 \mathrm{mg} / \mathrm{kg} /$ day in week 6 . Doses for sucralose ranged from $1.8-2.6 \mathrm{mg} / \mathrm{kg} / \mathrm{day}$ in wk 1 to $4.9-6.7 \mathrm{mg} / \mathrm{kg} /$ day in week 6 . NNS doses were well below the reported toxic level of $4 \mathrm{~g} / \mathrm{kg} / \mathrm{day}$ for aspartame (Magnuson et al. 2007) and 10g/kg/day for sucralose (Goldsmith 2000) and met the FDA defined Acceptable Daily Intake $(50 \mathrm{mg} / \mathrm{kg}$ bw/d and $5 \mathrm{mg} / \mathrm{kg}$ bw/d for aspartame and sucralose respectively (US FDA 2015). . Initial body weight was not different between groups ( $P=0.13$ ); animals were weighed weekly to adjust dosage of NNS for growth. This study was reviewed and approved by the University Institutional Animal Care and Use Committee.

After six weeks of treatment, an oral glucose tolerance test was administered. Following an overnight fast (14 h), a blood sample for glucose and insulin was taken by tail clip prior to administering a $2 \mathrm{~g} / \mathrm{kg}$ dose of a $50 \%$ weight/volume dextrose solution by gavage and samples were taken at $15,30,60$, and 
120 minutes after dosing. Blood glucose was measured immediately by a glucose meter (Ascensia Contour, Bayer HealthCare, Indianapolis, Ind. U.S.A) and test strips. Blood samples (300 $\mu$ l) for insulin were collected into micro capillary tubes. Samples were centrifuged, and plasma was removed and stored at $-70^{\circ} \mathrm{C}$ for later analysis by radioimmunoassay (Millipore Corp, Billerica, Mass., U.S.A.).

Following the OGTT, rats were euthanized and lean body mass and fat mass were determined by dual energy $x$-ray absorptiometry (DEXA) with small animal software (Lunar Prodigy, General Electric, Madison, Wisc., U.S.A.). The epididymal fat pads were then removed and weighed.

Statistical Analysis. Statistical analysis was performed with Statistical Package for the Social Sciences (SPSS) 22.0 software (Armonk, New York). One-way analysis of variance (ANOVA) and post hoc Tukey's tests was used to identify the differences in the dependent measures between groups. Significance was set to $p<0.05$. Areas under the glucose and insulin response curves (AUC) were calculated via the trapezoid method. Data are reported by analyzing the mean \pm SEM.

\section{$\underline{\text { Results }}$}

The response to an oral glucose load is shown in Figure 1. Fasting glucose $(P=0.232)$ and insulin $(P=0.427)$ were not different between groups (Figure $1 A$ and $1 B)$. No differences were found at any time point for the glucose or insulin response to the oral glucose load. Glucose AUC was not significantly different from control AUC for aspartame or sucralose groups $(P=0.28)$ (Figure $1 C$ ). The insulin AUC was also not different for aspartame or sucralose groups versus control ( $P=0.52)$ (Figure 1D). The rate of weight gain was similar between the treatment groups and the control group, averaging $66 \mathrm{~g} / \mathrm{wk}$ for the first three weeks and $35 \mathrm{~g} / \mathrm{wk}$ for week four. Total weight gain was $233 \pm 10 \mathrm{~g}$ for the aspartame and $249 \pm 5 \mathrm{~g}$ for the sucralose versus $239 \pm 5 \mathrm{~g}$ for the control group $(\mathrm{P}=0.27)$. Results of the body composition analysis are shown in Table 1. Percent body fat was not different between the aspartame group or the sucralose group versus the control group $(P=0.24)$. However, the weight of the epididymal fat pads was $20 \%$ greater in the aspartame treated rats than in the control animals $(P=0.042)$. No differences were found between either the aspartame group or the sucralose group and the control group for trunk fat $(P=0.32)$, total fat $(P=0.49)$, or the ratio of trunk fat to total fat $(P=0.07)$.

\section{$\underline{\text { Discussion }}$}

Although presumed to be metabolically inert, NNS consumption has been associated with weight gain and altered glucose tolerance in some human and animal studies (Fowler 2016), suggesting that NNS 
may, in fact, have metabolic effects. Possible mechanisms for the metabolic activity of NNS include altered ability to compensate for calories expected by sweet taste (Swithers et al. 2009; Davidson et al. 2011), alterations in the gut microbiota processing of nutrients (Palmnas et al. 2014; Abou-Donia et al. 2008; Suez et al. 2014) and/or inhibition of intestinal alkaline phosphatase (Gul et al. 2017). Neither the area under the glucose response curve nor the area under the insulin response curve was different between aspartame treatment or sucralose treatment compared with control in response to an oral glucose load. Similarly, the rate of weight gain and the total weight gained was not different between either NNS treated group or the control group.

A hyperglycemic response to an oral glucose load was found when NNS were delivered in the diet (Swithers et al. 2012), or drinking water (Suez et al. 2014; Palmnas et al. 2014; Mitsutomi et al. 2014; Gul et al. 2017) indicating a disconnect between the sweet taste and the learned response to control energy balance. However, when the glucose load was given by gavage bypassing the oral taste receptors, as in this study, a normal response to the glucose load was observed (Swithers et al. 2012). Conversely, glucose AUC was higher in response to an intraperitoneal glucose load in high-fat fed mice (Gul et al. 2017) and in mice with dietary-induced obesity (Mitsutomi et al. 2014) treated with aspartame. Palmnas et al. (2014) found a higher glucose AUC in high fat-fed rats than in chow-fed rats, but no separate effect of aspartame on glucose AUC in either group, however insulin stimulated glucose disposal was impaired in both the aspartame treated groups. Similarly, NNS ingestion has been shown to alter the glycemic response to an oral glucose load in high-fat fed rats (Suez et al. 2014) and in obese human subjects (Pepino et al. 2013), but not in healthy lean subjects (Ma et al. 2010). The finding of no effect of either aspartame or sucralose consumption on glucose tolerance in lean rats in this study is consistent with these findings. These results suggest that fat feeding and/or obesity may be predisposing factors for the altered glucose response to NNS consumption.

Studies in which the animals did not have an alternative to the consumption of aspartame or sucralose reported a slower rate of growth or no difference in weight compared with control animals (Palmnas et al. 2014; Mitsutomi et al. 2014; Goldsmith 2000; Beck et al. 2002), as was found in this study. Although the weight gain was the same for the aspartame and sucralose groups compared with the control group, an effect of NNS on body composition was noted. Epididymal fat pad mass was significantly increased in aspartame treated rats, as also reported in mice (Mitsutomi et al. 2014; Collison et al. 2013). Since epididymal fat pads may relate to visceral adiposity in humans (Gesta et al. 2006), these results suggest that NNS may induce a change in body composition. Conversely, the ratio of trunk fat to total fat 
trended lower in the sucralose treated animals compared with the control animals suggesting a relative reduction in abdominal obesity. Together, these findings suggest that changes in body composition may be related to the specific NNS consumed.

In summary, the results of this study showed no adverse effect of low-dose aspartame or sucralose consumption on glucose metabolism. While total weight gain and percent body fat were not different between either NNS group and the control group, an increase in abdominal fat was found with aspartame while the ratio of trunk to total fat trended lower with sucralose. These results are consistent with the findings of metabolic effects of NNS independent of weight gain.

The authors report no conflicts of interest associated with this manuscript. 


\section{$\underline{\text { References }}$}

Abou-Donia, M.B., El-Masry, E.M., Abdel-Rahman, A.A., McLendon, R.E., and Schiffman, S.S. 2008. Splenda alters gut microflora and increases intestinal p-glycoprotein and cytochrome $\mathrm{p}-450$ in male rats. J. Toxicol. Environ. Health. A. 71(21): 1415-1429. doi: 10.1080/15287390802328630.

Baker, H.J., Lindsey, J.R., and Weisbroth S.H. 2006. Normative values. In The Laboratory Rat, $2^{\text {nd }}$ ed. Edited by M.A. Suckow, S.H. Weisbroth, and C.L. Franklin. Elsevier Academic Press, San Diego, Cal. Pp 83-884.

Beck, B., Burlet, A., Max, J.P., and Stricker-Krongrad, A. 2002. Effects of long-term ingestion of aspartame on hypothalamic neuropeptide $Y$, plasma leptin and body weight gain and composition. Physiol. Behav. 75(1-2): 41-47.

Collison, K.S., Makhoul, N.J., Zaidi, M.Z., Inglis, A., Andres, B.L., Ubungen, R., Saleh, S., and Al-Mohanna, F.A. 2013. Predieabetic changes in gene expression induced by aspartame and monosodium glutamate in trans fat-fed C57BI/6J mice. Nutr. Metab. 10:44. doi: 10.1186/1743-7075-10-44.

Davidson, T.L., Martin, A.A., Clark, K., and Swithers, S.E. 2011. Intake of high-intensity sweeteners alters the ability of sweet taste to signal caloric consequences: implications for the learned control of energy and body weight regulation. Q. J. Exp. Psychol. (Hove). 64(7): 1430-41. doi:

10.1080/17470218.2011.552729.

Fowler, S.P.G. 2016. Low-calorie sweetener use and energy balance: Results from experimental studies in animals, and large-scale prospective studies in humans. Physiol. Behav. 164(Pt B): 517-523. doi: 10.1016/j.physbeh.2016.04.047.

Gesta, S., Bluher, M., Yamamoto, Y., Norris, A.W., Berndt, J., Kralisch, S., Boucher, J., Lewis, C., and Kahn, C.R. 2006. Evidence for a role of developmental genes in the origin of obesity and body fat distribution. Proc. Natl. Acad. Sci. USA, 103(17): 6676-6681.

Goldsmith, L.A. 2000. Acute and subchronic toxicity of sucralose. Food Chem. Toxicol. 38(Suppl 2): S53S69.

Gul S.S., Hamilton, A.R.L., Munoz, A.R., Phupitakphol, T., Liu, W., Hyoju, S.K., Economopoulos, K. P., Morrison, S., Hu, D., Zhang, W., Gharedaghi, M.H., Huo, H., Hamarneh, S. R. and Hodin, R. A. 2017. Inhibition of the gut enzyme intestinal alkaline phosphatase may explain how aspartame promotes glucose intolerance and obesity in mice. Appl. Physiol. Nutr. Metab. 42: 77-83.

dx.doi.org/10.1139/apnm-2016-0346.

Ma, J., Chang, J., Checklin, H.L., Young, R.L., Jones, K.L., Horowitz, M., and Rayner, C.K. 2010. Effect of the artificial sweetener, sucralose, on small intestinal glucose absorption in healthy human subjects. Br. J. Nutr. 104(6): 803-806. doi: 10.1017/S0007114510001327.

Magnuson, B.A., Burdock, G.A., Doull, J., Kroes, R.M., Marsh, G.M., Pariza, M.W., Spencer, P.S., Waddell, W.J., Walker, R., and Williams, G,M. 2007. Aspartame: a safety evaluation based on current use levels, 
regulations, and toxicological and epidemiological studies. Crit. Rev. Toxicol. 37(8): 629-727. doi: $\underline{10.1080 / 10408440701516184}$

Mitsutomi, K., Masaki, T., Shimasaki, T., Gotoh, K., Chiba, S., Kakuma, T., and Shibata, H. 2014. Effects of a nonnutritive sweetener on body adiposity and energy metabolism in mice with diet-induced obesity. Metabolism, 63(1): 69-78. doi: 10.1016/j.metabol.2013.09.002.

Palmnas, M.S.A., Cowan, T.E., Bomhof, M.R., Su, J., Reimer, R.A., Vogel, H.J., Hittel, D.S., and Shearer, J. 2014. Low-dose aspartame consumption differentially affects gut microbiota-host metabolic interactions in the diet-induced obese rat. PloS one, 9(10): e109841. doi: 10.1371/journal.pone.0109841.

Pepino, M.Y., Tiemann, C.D., Patterson, B.W., Wice, B.M., and Klein, S. 2013. Sucralose affects glycemic and hormonal responses to an oral glucose load. Diabetes Care, 36(9): 2530-2535. doi: 10.2337/dc122221.

Swithers, S.E., Baker, C.R., and Davidson, T.L. 2009. General and persistent effects of high intensity sweeteners on body weight gain and caloric compensation in rats. Behav. Neurosci. 123(4): 772-780. doi: $10.1037 / a 0016139$.

Swithers, S.E., Laboy, A.F., Clark, K., Cooper, S., and Davidson, T.L. 2012. Experience with high-intensity sweetener saccharin impairs glucose homeostasis and GLP-1 release in rats. Behav. Brain Res. 223(1): 114. doi: 10.1016/j.bbr.2012.04.024.

Suez, J., Korem, T., Zeevi, D., Zilberman-Schapira, G., Thaiss, C.A., Maza, O., Israeli, D., Zmora, N., Gilad, S., Weinberger, A., Kuperman, Y., Harmelin, A., Kolodkin-Gal, I., Shapiro, H., Halpern, Z., Segal, E., and Elinav, E. 2014. Artificial sweeteners induce glucose intolerance by altering the gut microbiota. Nature, 514(7521): 181-186. doi: 10.1038/nature13793.

[US FDA] U.S. Food and Drug Administration. 2015. Additional information about high-intensity sweeteners permitted for use in Food in the United States [Internet] U.S. Food and Drug Administration (US FDA), Center for Food Safety \& Applied Nutrition (CFSAN) [cited 2017 Jun 11]. Available from:

http://www.fda.gov/Food/IngredientsPackagingLabeling/FoodAdditivesIngredients/ucm397725.ht m [Page Last Updated: 05/26/2015]. 
Table 1. Animal Characteristics

\begin{tabular}{lccc}
\hline & Aspartame & Sucralose & Control \\
\hline Initial Body Weight (g) & $147 \pm 2$ & $153 \pm 3$ & $152 \pm 1$ \\
Final Body Weight (g) & $380 \pm 10$ & $402 \pm 7$ & $392 \pm 5$ \\
Lean Mass (g) & $303.6 \pm 8.6$ & $325.5 \pm 6.9$ & $316.4 \pm 6.4$ \\
Body Fat \% & $19.3 \pm 0.70$ & $17.7 \pm 0.67$ & $17.6 \pm 0.91$ \\
Trunk Fat (g) & $40.9 \pm 2.9$ & $35.4 \pm 1.5$ & $41.8 \pm 4.4$ \\
Total Fat (g) & $73.1 \pm 3.9$ & $69.5 \pm 2.6$ & $67.2 \pm 3.8$ \\
Ratio Trunk Fat:Total Fat & $.547 \pm .037$ & $.487 \pm .006$ & $.602 \pm .044$ \\
Epididymal Fat (g) & $5.50 \pm 0.34^{*}$ & $5.00 \pm 0.24$ & $4.55 \pm 0.19$ \\
Bone Mineral Density (g/cm ${ }^{2}$ ) & $0.170 \pm 0.003$ & $0.171 \pm 0.003$ & $0.166 \pm 0.002$ \\
Fasting Blood Glucose (mmol/L) & $2.93 \pm 0.16$ & $3.27 \pm 0.11$ & $3.02 \pm 0.15$ \\
Plasma Insulin (pmol/L) & $129.4 \pm 12.0$ & $117.8 \pm 22.8$ & $152.0 \pm 20.4$ \\
\hline
\end{tabular}

Values are mean \pm SEM. *Significantly different from Control, $\mathrm{P}<0.05$; 
Figure Legends

Figure 1. Results of Oral Glucose Tolerance Test. Glucose (A) and insulin (C) response to oral glucose load. Area under concentration curve for glucose (B) and insulin (D). No significant difference between either aspartame or sucralose and control condition. Values are mean $\pm \mathrm{SEM}$. 

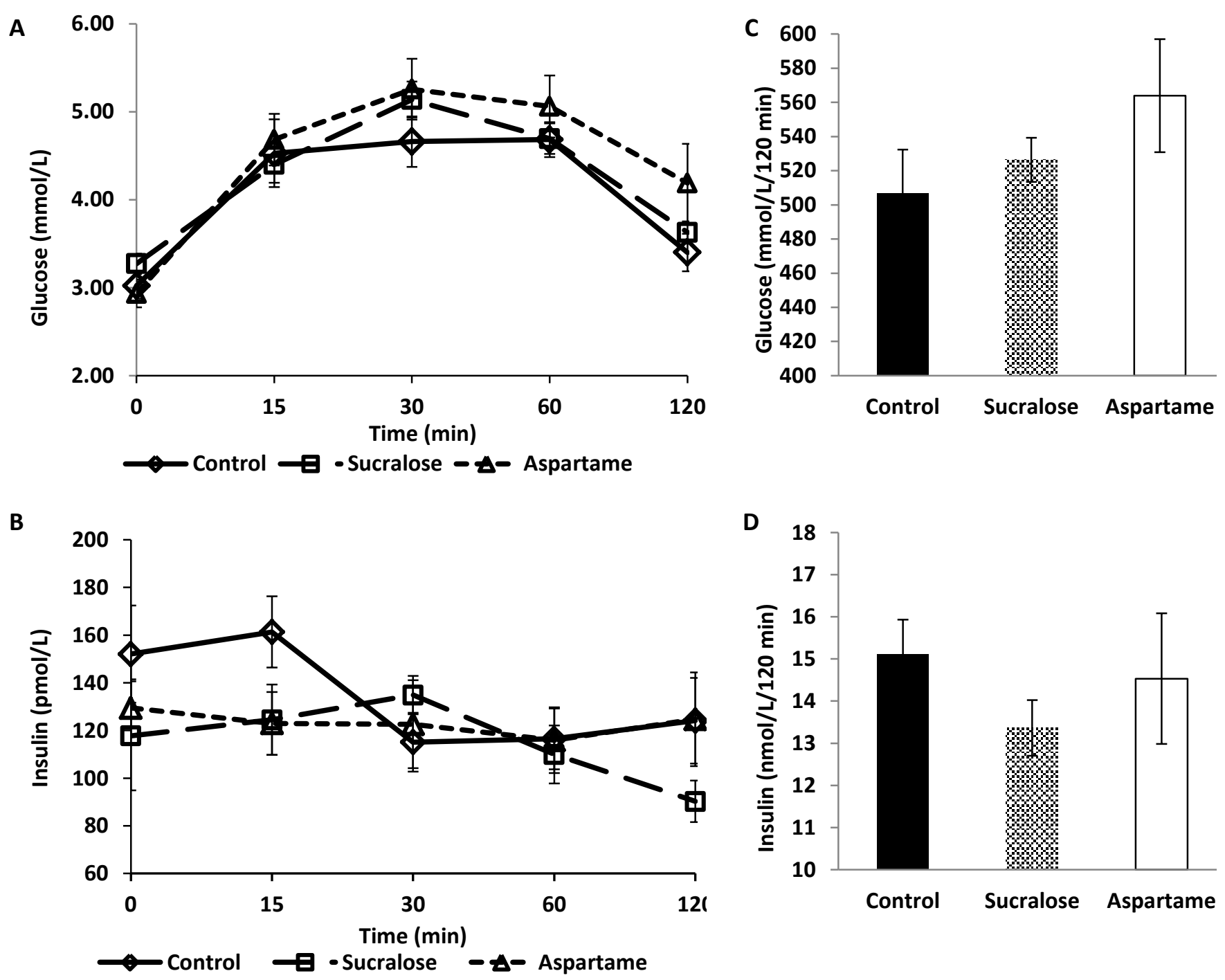